\title{
Embedding virtual environments into the physical world: memorability and co-presence in the context of pervasive location-based games
}

\author{
Paula Alavesa ${ }^{1}$ (D) Minna Pakanen ${ }^{1,2} \cdot$ Timo Ojala $^{1} \cdot$ Matti Pouke $^{1} \cdot$ Hannu Kukka $^{3} \cdot$ \\ Alexander Samodelkin ${ }^{4}$ - Alexander Voroshilov ${ }^{5}$ - Mohamed Abdellatif ${ }^{1}$
}

Received: 8 March 2018 / Revised: 30 October 2018 / Accepted: 12 December 2018/

Published online: 27 December 2018

(C) The Author(s) 2018

\begin{abstract}
Realistic 3D virtual environments, such as existing city models, have the potential to be used in pervasive games as a passageway between physical and virtual. Smooth attention displacement and transitions between these two realities are largely unexplored in the context of pervasive gameplay. We conducted two field trials using a pervasive live action role playing game to study the effect moving between the virtual and the physical has on co-presence and memorability. Although differences in co-presence during gameplay were small, they highlight the subtleties in the social structuring of pervasive gameplay. Spatial similarity between the physical and virtual environments made the $3 \mathrm{D}$ virtual environments more memorable. We identify two important issues to consider in embedding virtual environments into pervasive games: structuring of social interactions and the spatial realism of the VEs.
\end{abstract}

Keywords Location based mobile games · Pervasive games $\cdot$ Co-presence $\cdot$ Memorability · Player experience

Paula Alavesa

paula.alavesa@oulu.fi

Minna Pakanen

Denmarkmpakanen@eng.au.dk

1 Center for Ubiquitous Computing, University of Oulu, P.O Box 4500, FI-90014 Oulu, Finland

2 Socio-Technical Design, Department of Engineering, Inge Lehmanns Gade 10, 8000 Aarhus C, Aarhus, Denmark

3 Boogie Software Ltd., Kasarmintie 15, 90130 Oulu, Finland

4 Adminotech Ltd., Hallituskatu 13, 90100 Oulu, Finland

5 Elektrobit Automotive Finland Ltd., Elektroniikkatie 13, 90590 Oulu, Finland 


\section{Introduction}

Pervasive games take advantage of physical urban infrastructure and latest technological advancements in creative ways to compose gameplay that expands what is considered traditional gaming [18, 33, 37].

Virtual environments (VEs) that resemble physical environments are already being used in many existing games. Often the game environment is simplified to a streamlined version of the physical environment to meet the requirements of game scene design [19, 28, 41]. However, aesthetic as well as geographically accurate virtual city models are becoming increasingly accessible $[1,54]$. In addition to being used in simulation training, and visualizing change for collaborative city planning [2], virtual city models have the potential to be used as game scenes for both traditional digital games as well as pervasive games. Realistically proportioned game scenes provide a direct link between the physical and the virtual world, which in turn enables direct visualization of player movements or other sensor data from physical locations. This link between physical and virtual worlds comes into focus when designing games where VEs are embedded into the context of pervasive gameplay.

In pervasive games utilizing both real and virtual environments, not only the properties of the VE dictate the player experience. Pervasive games are entwined with daily life, and are most often played in locations that provide unexpected interactions especially with bystanders [37]. While pervasive or other kinds of displays located or situated in urban environments can provide a window on the world [21,34] to blend the physical and the virtual world [14], smooth attention displacement between the two can be a challenge if the window on the world is not truly mobile, as with smart phones or other portable devices. The busyness, and other qualities of the locations where the VEs are accessed, may affect the gameplay.

Daily life cannot be observed in the controlled environment, hence we chose in the wild research methodology $[11,13]$. We aimed at exploring measurable aspects in player experience to gain knowledge on the smooth cognitive linking of physical and virtual worlds in the context of pervasive games. We conducted two [13] field trials with a game called City Knights (Fig. 1) to explore attention displacement using situated displays as the window on the world. We used a mixed method approach gathering both qualitative and quantitative data from the trials. In field trial one (FT1), we studied co-presence when using situated displays by combining experience sampling method (ESM) [30] and qualitative observations with nine participants. In field trial two (FT2), we focused on the memorability of the VEs in relation to the spatial qualities of the physical locations with 13 participants in a qualitative interview study. We explored relevant literature in player experience such as memorability, presence and
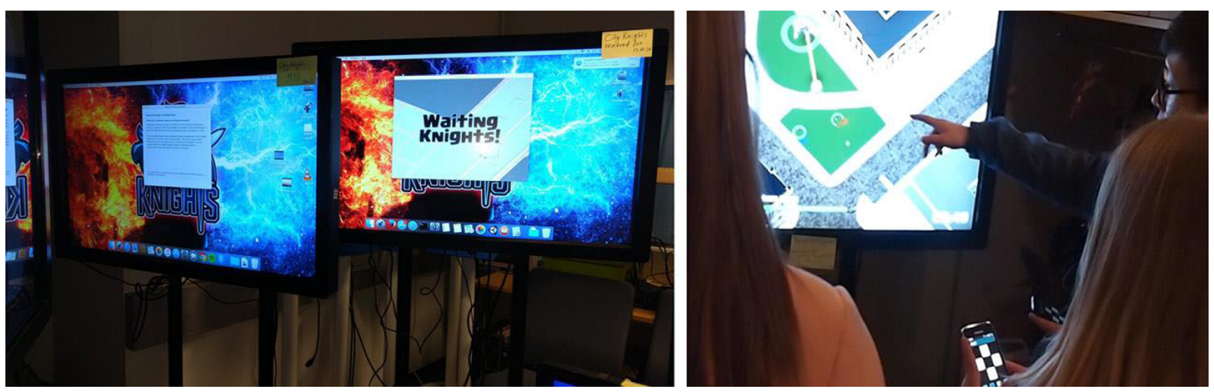

Fig. 1 City Knights displays waiting to be situated downtown (left) and an ongoing boss-fight by a display (right) 
immersion to structure a theoretical framework for analyzing our results and their relation to overall player experience.

\section{Background}

The physical environment offers a rich and unpredictable arena for digital games [18, 32, 37]. However, the context of pervasive gameplay provides challenges for game design and scientific investigation. In addition, targeting the traditional elements in player experience, such as immersion, presence and flow for measurement is not straightforward.

\subsection{Context of pervasive gameplay}

Pervasive games expand what is traditionally considered gaming. Montola classifies the expansions into three categories: the spatial, temporal and social [37]. These expansions can be considered to outline the context of gameplay, as pervasive games take place in physical space in realtime. The third expansion implies that pervasive games are inherently social; the games are often played with multiple players and can include interactions with non players i.e. bystanders. Furthermore, pervasive games are intrinsically entwined with daily life, which can be considered an additional context defining feature. Despite the strong conceptual connection to the physical environment, the current pervasive games are in addition mostly digital. They take advantage of the ubiquitous computing infrastructure of modern cities. Hybrid space is a holistic description of modern urban space encompassing the technological and the social aspects of space. Therefore, viewing pervasive games as playful appropriations of hybrid space $[18,46]$ strengthens the conceptual entanglement of the physical and digital layers of gameplay. Despite this entanglement embedding digital VEs into the context of pervasive gameplay is not self-evident. If the players are provided with access to both physical and virtual, one or the other prevails [3, 7]. However, there are few games where the physical and virtual game scenes have been blended successfully. Typical example is Pokemon GO, that features a game scene projected on a mobile phone screen in a simplistic manner i.e. a map enhanced with a few 3D objects and an avatar [45]. This is because map-based projection of reality are the simplest, but also the most mobile virtual environments [20]. In this study we however were looking into embedding more realistic mirror world [25] like VEs into the game arena. Realistically and aesthetically detailed city models are readily available can be used in various applications, including games [1,8]. High level of realism makes it possible to create situations where the player can step into the virtual environment from the physical either through a display or using virtual reality gear. This situation where attention shifts between physical and virtual is the target of this study.

\subsubsection{Attention displacement between physical and virtual environments}

Smooth attention displacement between the physical and virtual environments poses a challenge for creating games where both physical and virtual elements are used, especially if the provided window on the world $[14,21]$ is not truly mobile as it can be with a map based projections. Augmented reality (AR) is one option for blending partial contents from the virtual as a direct projection onto the physical. AR however has a high battery consumption on mobile equipment [24] and is therefore often offered as an option inside a game app and can be 
toggled on or off without disrupting game play. As a result, the AR option is not often used by players $[44,45]$.

\subsection{Memorability and co-presence in relation to presence and immersion}

According to Slater [52], presence has three aspects: the sense of being there, individual's recognition of what is there as real or present, and a memory of "there" as a real place. Prior research suggests that presence should be considered an everyday phenomenon and a "basic property of normal conscious experience". Therefore, isolating measurements of presence in experiences combining VE and physical environment can be difficult $[16,39,52,56]$. Memorability can be seen as an important aspect of immersion, and through this connection an important contributor to the game flow itself.

\subsubsection{Memorability}

When mere 2D images are used for depicting locations, memorability is more related to the semantic qualities of an image than their unusualness or visual esthetics [31, 50]. Similar findings have been reported regarding memorability of 3D VEs [26, 47, 57]. Among others, semantic qualities affecting the memorability of virtual environments are known landmarks [57], which relate to the mental maps [35, 47] created by the VE users. Memorability and memory tests have been used as one measurable aspect in assessing the level of presence in virtual environments [9]. When people navigate a new environment, their prior experience affects how they perceive, comprehend, or retain the new information. This process is described in schema theory, which suggests that perception, language comprehension, and memory are processes which involve the interaction of new information with the old, schemabased information. Schemas are knowledge structures and can be represented in a VE they as a landmarks, objects that fit that particular context, or in our case the location where the VE is accessed in relation to what is projected in the located display [10, 35].

Schema theory states that memory retrieval is further schema related. Schema-based information may be used in the process of retrieving information from memory. When people are exposed to large amounts of information, they ingest more information than they can communicate when recalling is required. Schema theorists suggest that schemata are further used to guide the search for information from memory. Information which is not related to the schema will be harder to recall than information which is schema related [10], therefore there should be a difference in how people perceive they remember information of a virtual environment to how well they actually remember the details from that location when enquired further. People may remember they recognized a location, but at another level when they have not acquired a good mental map or schema of that location they may have trouble both remembering what that location was or how it was detailed.

\subsubsection{Co-presence}

Presence can be considered as a property of daily life and a very subjective experience [29, 53, 56], whereas co-presence requires observable facilitation of human interaction. Smooth attention displacement is required for optimal flow, an uninterrupted experience of doing. Much like presence, flow is difficult to measure in daily life [38]. Optimal flow can further be an isolating state of mind [15]. Therefore, we focus on the influence moving between physical 
and virtual has on co-presence. Co-presence, as defined by Goffman [27], is a sense of being close enough to perceive others. It can culminate into a sense of acknowledging that people perceive that they are being perceived by other people [27]. Social presence is a sense of intimacy and saliency of the connection one has to another person, whereas co-presence does not necessarily require other than the sense of being there with someone [42]. Physical colocation is one model for facilitating co-presence, but co-presence can also be sensed in mediated environments such as $3 \mathrm{D}$ VEs as it does not necessarily require physical colocation [6]. According to hybrid reality logic [17, 18] one defining feature of modern urban space are the social interactions available. In addition the current studies state that social aspects in pervasive gameplay are key motivators for the players [23, 43, 57]. For these reasons, in addition, co-presence is a valid target for pervasive games research.

Spatial realism in relation to memorability and co-presence sensed during co-located gameplay by virtual environments has not been researched in the context of pervasive games where the transitions from virtual to physical are blurry and mere presence (as in daily life) is persistent [56]. Spatial expansion is one of the key elements of pervasive games [37], which can take place in physical and virtual arenas spanning through the globe [37, 39, 45]. For this reason, we are interested in the transition between the physical world and the VE, with a specific focus on situations where a transition in attention displacement, and therefore a seam or a rift in presence, occurs. This differs slightly from what Slater calls breaks in presence (BIP) that take place when immersed in the VE [51] as the players in our case move between the VEs and the physical environment. The point of transition is dictated by game mechanics, so we cannot deduct much from the frequency of events [52]. Instead, we study co-presence while using situated displays to map the social aspect of gameplay in relation to the characteristics of the locations where the VEs are embedded, i.e. where the displays are physically situated. We also investigate the semantic linking of the VEs and the physical world by spatial similarity, where because of the lack of player experience items (immersion, flow, presence) that are measurable in the field, we study changes in co-presence during gameplay and memorability in relation to the spatial similarity between virtual and physical spaces.

\section{City Knights}

City Knights $[4,49]$ is a location based mobile game that takes place in downtown urban area. The underlying game design follows that of typical pervasive live action RPGs. Each game round involves three distinct phases: quests, conquering a location and a "boss-fight". There are no technical restrictions on team size or the number of teams. So far, tournaments have been conducted with 3-4 teams of 3-5 players. In presenting the gameplay of City Knights we a focus on the boss-fights (Fig. 1). This stage is where the players access realistic VEs through situated displays, thus where the attention displacement from the physical location to the virtual environment takes place. The models for the VEs are from the downtown Oulu, Finland.

\subsection{Gameplay}

Pervasive games often use elements of role-playing games (RPGs) in the game design to create digitally enhanced live action RPGs [37]. City Knights' game design and the game mechanics are influenced by this tradition. The players play in teams, collect awards to gain items and 
gear to aid them in an epic battle against foes. The game has three distinct phases: 1) quest phase, 2) conquering a location and 3) a boss-fight.

During the quest phase of the game, the players roam around the city searching for QR codes (Fig. 2). They are aided by hints given by the mobile game application. Completed quests give players in-game currency they can use buy consumable and equippable items from the game store.

Once players have accumulated a sufficient amount of equipment for a boss-fight, they can attempt to conquer a location around a specific situated display. These locations are ring shaped zones within 10-60-m radius around the displays. The zones are further divided into five sections (Fig. 3a) that can be separately occupied by different team members to conquer the location faster. During this phase the players may be competing of the ownership of the location with a nother team, therefore collaboration is beneficial. The game design is meant to inspire team collaboration and coordination, and to provide different social setting in comparison to the other two game phases; in quests players are dispersed around the city and in bossfights players are co-located by a display. Once the players have conquered a location, they gather by a situated display at the center of that specific zone to gain access to the VE that hosts the boss they need to defeat. Each game round culminates into a boss-fight. The players can however play as many rounds as they like during one game event.

Players control the movement and behavior of their avatars with their mobile game application (Fig. 3c). A display has a conjoined view of the VE (Fig. 4), so that if an avatar moves further away, the view expands so that all avatars are always visible on the screen. If an avatar goes behind a building, a circular avatar highlight is visible atop the building. The top left corner of the display shows the current status of players' health (hit points).

The distance between the spawn point of avatars and the boss varied in the VEs. The spawn points were selected so that all of them are behind a corner from the boss so that the boss would not be instantly visible when players initiate a boss-fight. We wanted to give the players an opportunity to wander inside the scene and get used to the controls before engaging in the boss-fight.

The display shows a hovering text "Waiting for Knights" (Fig. 1) on top of the spawn point of the player avatars till the moment at least one of the players in a team has initiated the fight and is close by the screen. The players can wait for their fellow players to come to the site before searching and challenging the boss.

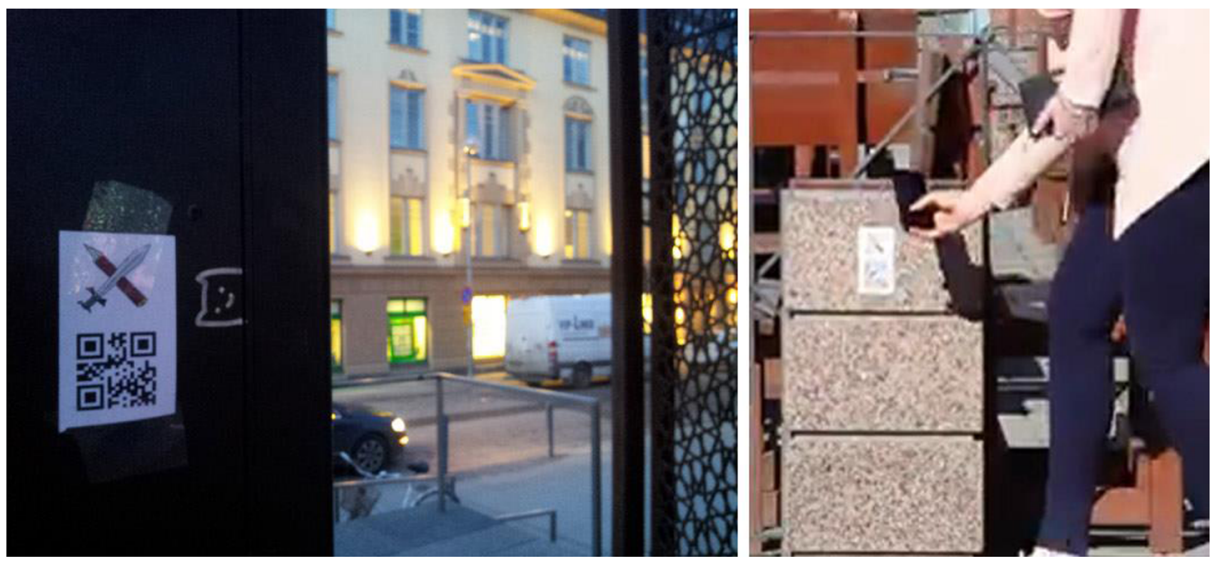

Fig. 2 City Knights quests have clues for finding QR codes that award game currency that can be used to purchase items. The piece of paper with the QR code is small, $3 \times 3 \mathrm{~cm}$, so that the hints provided by the game are needed to spot them in urban environment 


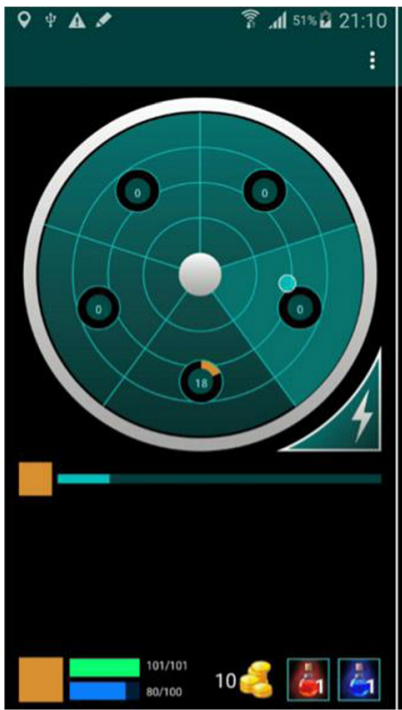

a

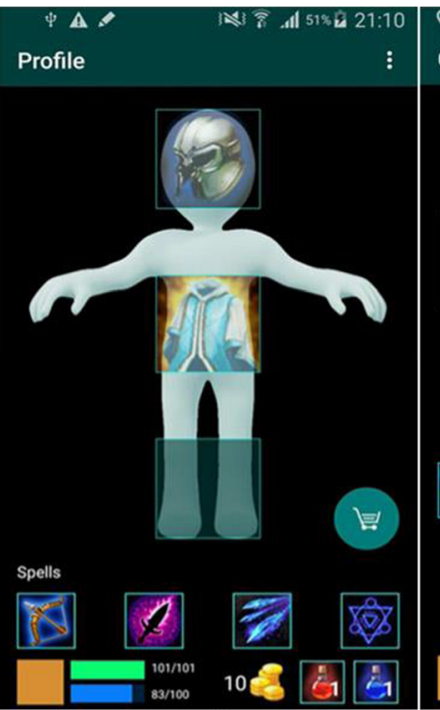

b

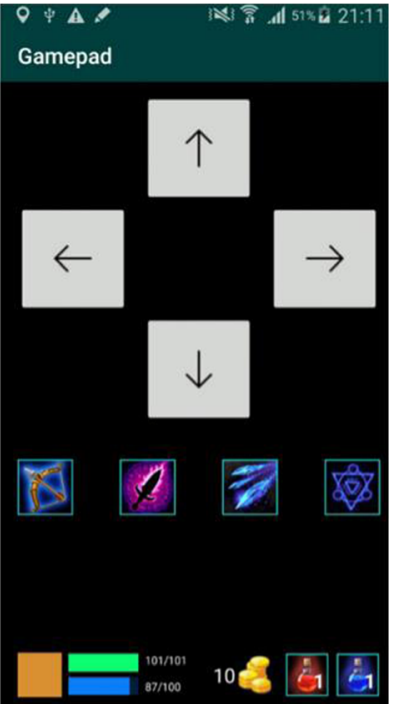

C

Fig. 3 Screenshots from the city knights mobile application. a The radar screen depicts a zone around the situated displays. This view is used when conquering a location. b The player inventory screen, shows the equippable items and has access to the game shop. c The app during the boss-fight has arrows for guiding the player avatar in VE, the weapons and spells that can be used in fights can also be seen in this view

\subsection{Virtual game scenes: the boss-fight arenas}

The first two game phases take place in the physical environment and encourage players to compete with each other, while the boss-fight is situated in a virtual environment comprised of areas from the virtual city. The $3 \mathrm{D}$ city has been built with a mirror world like similarity to the corresponding city. The scale of the game scenes is 1:1. The level of detail (LOD) in all the scenes is high, LOD8 (scale 1-9) in according to the definition of Biljecki et al. [8]. Although visual realism of the 3D VEs has been payed attention to, there is no audio or sound effects in the game scenes.

In City Knights, during a boss-fight, the players have an isometric view of the virtual game scenes. Players have avatars, they can control with their mobile applications, as previous work has shown that a sense of agency, possibility for task performance and avatar presence have a positive effect on presence [57]. Furthermore, avatars mediate interaction in the VE providing
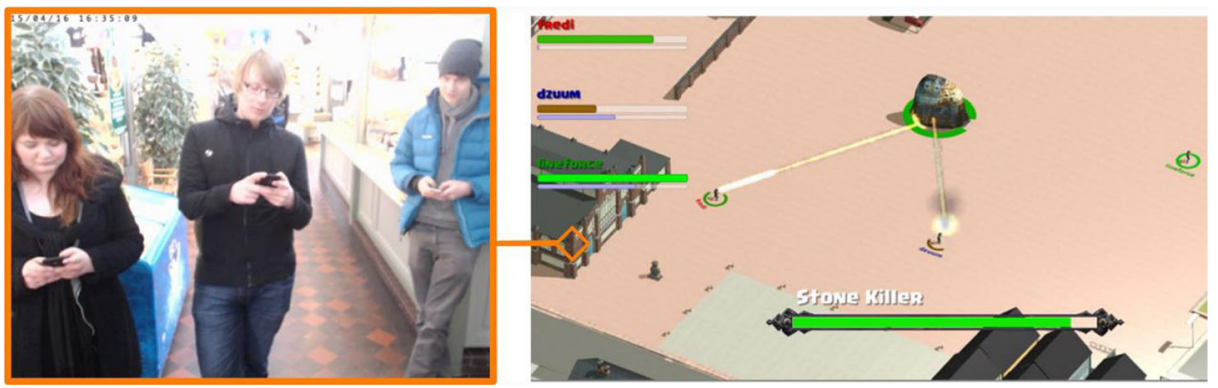

Fig. 4 Team of players by a display (left) fighting in the corresponding VE (right) in FT1 
an additional mode for co-presence [6]. Players control the movement and behavior of their avatars with their mobile game application (Fig. 3c, Fig. 4). A display has a conjoined view of the VE, so that if an avatar moves further away, the view expands so that all avatars are always visible on the screen. If an avatar goes behind a building, a circular avatar highlight is visible atop the building. The top left corner of the display shows the current status of players' health (hit points). The distance between the spawn point of avatars and the boss varied in the VEs. The spawn points were selected so that all of them are behind a corner from the boss so that the boss would not be instantly visible when players initiate a boss-fight. We wanted to give the players an opportunity to wander inside the scene and get used to the controls before engaging in the boss-fight (Fig. 5, Table 1).

\subsection{Technical implementation}

Figure 6 shows the high-level architecture of City Knights that involves a game server, a database, situated display(s) and smartphones. The situated displays host Unity [55]

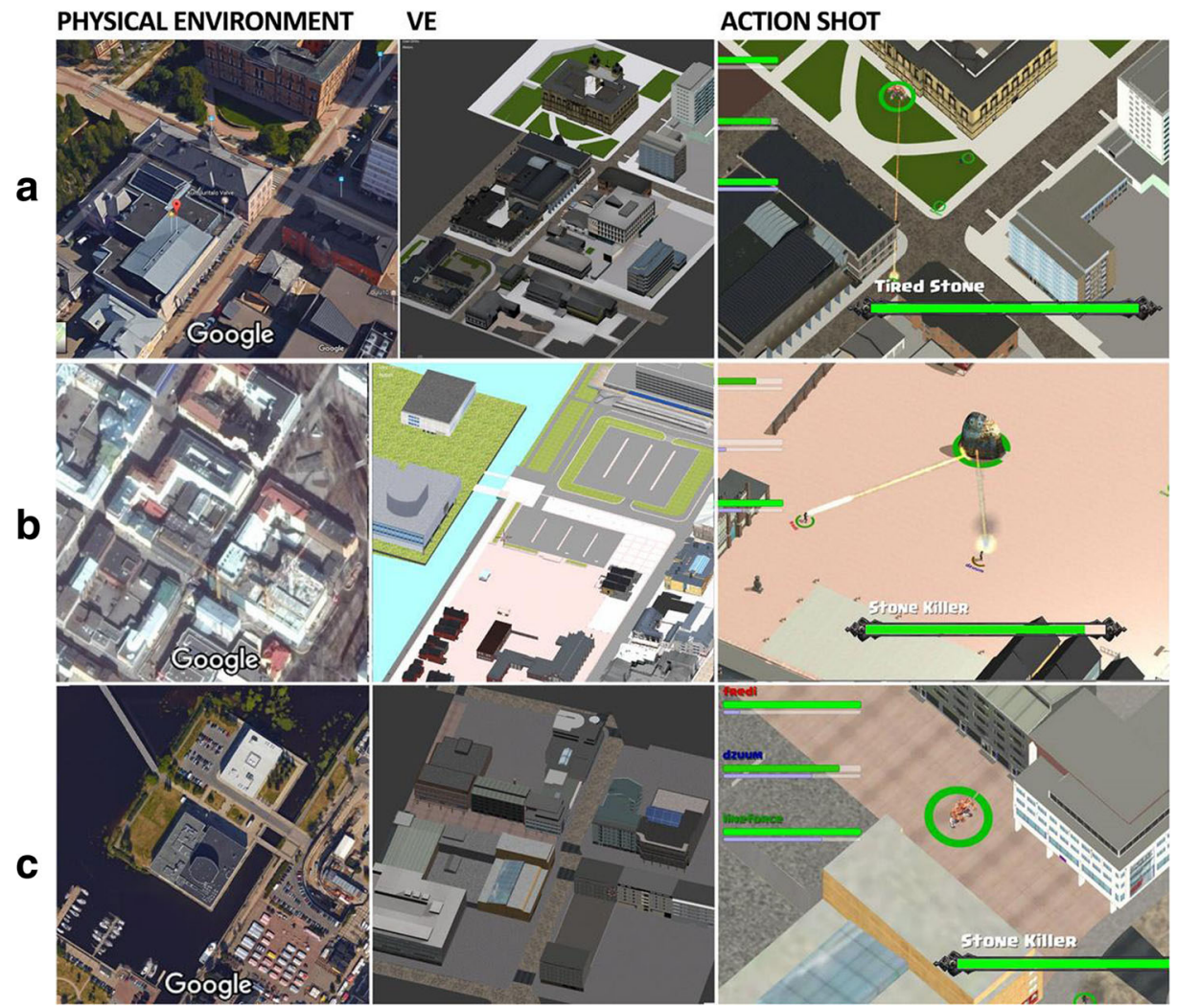

Fig. 5 Game scenes as they were in FT2, and to some extent, also in FT1. The first column depicts the physical area/location of each situated display. The second column is the corresponding VE, while the third shows an action shot of the boss-fight in that particular VE. The first row a is the location with spatial realism. Second row b shows the well known location with added landmarks. The boss of this scene was a less know landmark as well. The third row (c) shows the scene depicting a generic street corner from the game area. The game scenes a-c were used in FT2. In FT1 a was used as it is, while the VE from b was used inside the physical environment from c. The virtual game scene from c was not used in the FT1 
Table 1 Game scene details

\begin{tabular}{llll}
\hline Scene & $\begin{array}{l}\text { Avg. } \\
\text { polycount }\end{array}$ & $\begin{array}{l}\text { Distance between avatar } \\
\text { spawn point and display } \\
(\mathrm{m})\end{array}$ & $\begin{array}{l}\text { Distance between avatar } \\
\text { spawn point and boss } \\
(\mathrm{m})\end{array}$ \\
\hline $\begin{array}{l}\text { FT1: Secluded } \\
\begin{array}{l}\text { FT2: Well known location with spatial } \\
\text { similarity }\end{array}\end{array}$ & $203 \mathrm{k}$ & 31 & 61 \\
$\begin{array}{l}\text { FT1:Quiet and Buzy } \\
\text { FT2: Well known location }\end{array}$ & $220 \mathrm{k}$ & 420 & 80 \\
\begin{tabular}{l} 
FT2: Generic street corner \\
\hline
\end{tabular} & $30 \mathrm{k}$ & 545 & 121 \\
\hline
\end{tabular}

game scenes that communicate with the mobile game application running on Android smartphones via the dedicated server using REpresentational State Transfer (REST) and User Datagram Protocol/REST (UDP/REST) protocols. The mobile application is a native Android Java application. Game server upkeeps the game state and provides REST application programming interface (API) for handling requests. MySQL database provides persistent storage for game and player data and therefore stores and upkeeps the game state.

The displays are 46" full high density (HD) liquid-crystal display panels installed at eye height on movable stands, which is why they are not by definition pervasive displays as they are not a permanent part of the urban infrastruture. The displays host Unity [55] game scenes that communicate with the mobile game app running on Android smartphones via the server using REST and UDP/REST protocols.

The game is designed and implemented so that it can be set up for different events. The quests can be authored and situated using a web interface. Via web UI the game host can also adjust the locations of the situated displays and the contents of the embedded questionnaires.

\section{Field trials}

To study different aspects of presence (co-presence and memorability) in the context of pervasive games, we conducted two field trials. In the first field trial (FT1) we focused on co-presence by the embedded VEs, i.e. at the location of the situated displays. In the second field trial (FT2) our focus was on the memorability of the VEs in relation to the spatial qualities of the physical locations. We do not compare the results between trials but combine the understanding gained to form a more holistic view on embedding VEs into pervasive gameplay.

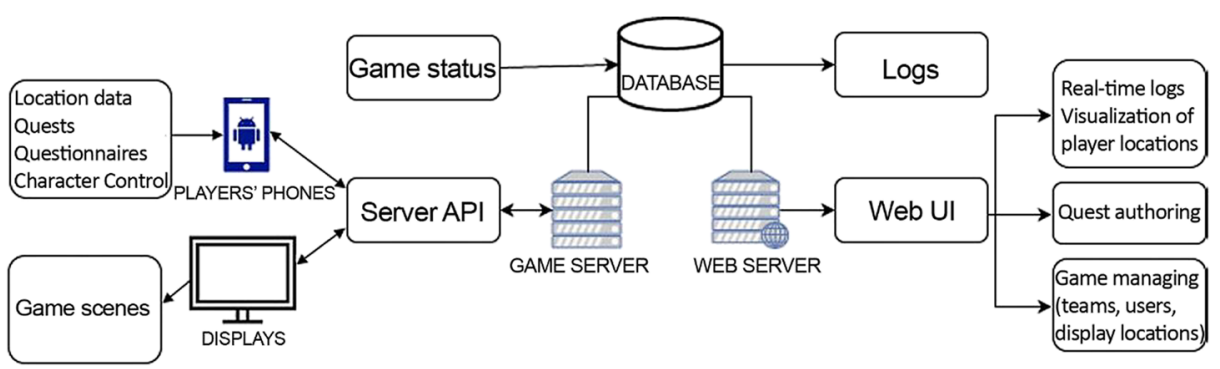

Fig. 6 The CK high-level architecture 

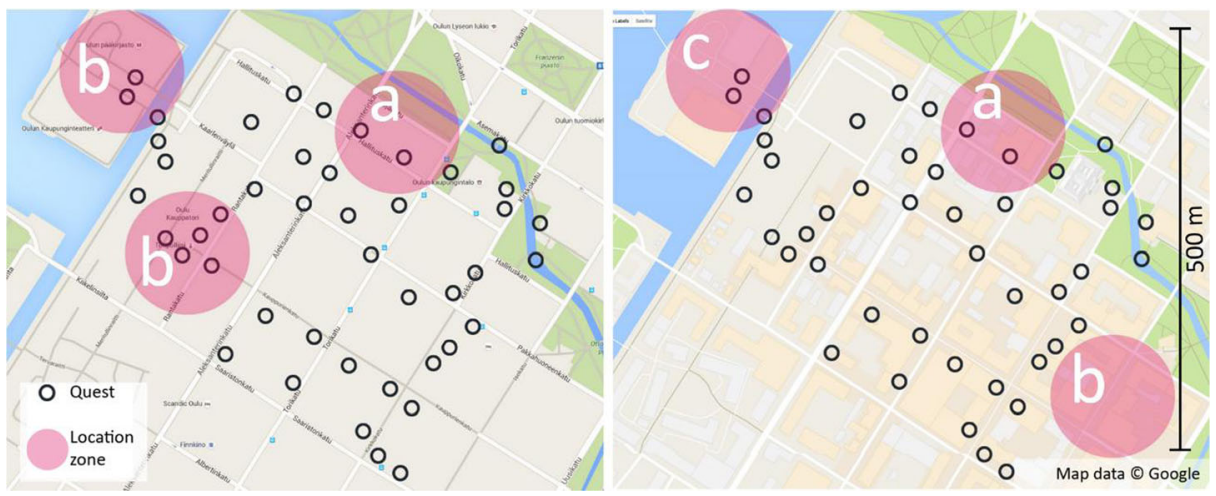

Fig. 7 Game area and the field trial setup of FT1 (left) and FT2 (right). A display was situated in the center of each Location zone. The difference betwee the two field trials is one display location and the game scenes projected on display locations. The a-c on the map refer to the 3D game scenes shown on display there and correspond to the letters in Fig. 5

\subsection{Setup}

The field trials were conducted in downtown urban area during April (FT1) and October (FT2) in 2016. The game setup remained the same between the trials. The QR codes were placed inside an area of $0.225 \mathrm{~km}^{2}$ (Fig. 7). The game area was otherwise undefined and the players were allowed to roam freely. We observed players' locations indirectly in real-time [36] and, based on our observations, went to observe their behavior also directly. This allowed us to confirm that the players never left the play area in either trial.

VE scenes in FT1 were spatially similar with their actual physical locations depicted with circular zones in Fig. 7 (left). In FT2, one of the displays was situated at a different location than depicted by the corresponding VE. In addition, the VE of the third display was replaced with a new VE representing a generic street corner. This was done for the purpose of exploring the significance of the spatial similarity on memorability of the game scenes. The detailing of the scenes between trials and game sites is similar, however site b (Fig. 5b; Table 1) does in addition depict some known landmarks. Site c (Fig. 5c; Table 1) is a generic street corner. Finally, the area a (Fig. 5a; Table 1) is a well-known location that further had spatial similarity to the site where it was accessed from.

\subsection{Participants}

Participants for both trials were recruited using the university mailing lists, social media, and a dedicated website. They signed up for the game by filling a prequestionnaire containing demographic questions. In addition, they provided informed concent for participating in the trials. Underage participants had to provide consent from their parents before being allowed to participate. The participants in FT2 further filled in the immersive tendencies questionnaire (ITQ) [59] during the sign-up to assess any individual differences in their reaction to game scenes. Two questions of the ITQ questionnaire were presented on site: "How mentally alert do you feel at the present time?" and "How physically fit do you feel today?" 
In FT1 there were nine participants with a mean age of $21(\mathrm{SD}=2.5)$ of whom three were female. In FT2, there were 13 participants with a mean age of $22.31(\mathrm{SD}=2.1)$ of whom three were female. In the FT1, only two out of nine had previous experience on location-based games, while in FT2, this number was twelve out of thirteen. This change can be explained with the summer 2016 release of Pokemon GO occurring between the trials. In FT1, the participants formed teams of three. In FT2, the team sizes were 5, 4 and 4. During both trials, the participants were allowed to borrow a smartphone as well as a $4 \mathrm{G}$ data sim card for the duration of the trials. Participants also had the opportunity to install the game application on their own phones, if they so preferred. Each participant was rewarded with a movie ticket worth of $10 €$ after both field trials.

The player teams were formed in advance according to prequestionnaires. Before the actual game rounds, the players were given a 15-25-min introduction to the game and the overall features of the application. After this, the players were sent off to play the game independently. Teams engaged in three 45-min game rounds with 15-min breaks in between allowing them to regroup.

\subsection{Research material}

The collected material comprised of pre-game questionnaires, field observations, video material as well as transcripts from semi-structured interviews conducted right after the trials. The semi-structured interviews conducted in FT1 focused on motivation, teamplay, co-play and how the gameplay changed between game rounds. In FT2 the interview structure was similar, but with added focus on memorability of the game scenes in different locations. The FT1 interviews took 10-12 min, while FT2 interviews took 20$30 \mathrm{~min}$. We also counted the people passing by the displays from the display video camera feeds. In FT1 we further used ESM [30] to collect data on experienced copresence during different game phases, at the location of different displays as well as during all three game rounds. The ESM questions were taken from the co-presence questionnaire [12] which itself is based on questionnaire on evaluating presence by Slater et al. [53]. The questionnaire contained four items, with Likert scale from 1 to 7 each. The questionnaire items were:

1. I had a sense I was in the same place as my team

2. I had a sense that my team was in a same place with me

3. I had a sense of us becoming more of a group in the last few minutes

4. I had a sense of being a part of a group over the last few minutes.

We used a short version of the the questionnaire to prevent player fatigue towards answering the same questionnaire so many time during the game. We emphasized to the players before the game, how important it is to answer the questions truthfully and consider their particular situation at the time of answering. Since we measured copresence on an ordinal scale and with same users throughout the experiment, we used repeated measures ANOVA for dependent groups to analyze the questionnaire data. Mauchly's test for sphericity was used to indicate whether assumption of sphericity was violated, and if so, necessary corrections were made. The interview material from FT2 went through more thorough analysis and coding with agreement testing, whereas FT1 interview transcripts went through a process of eclecting coding. 


\section{Analysis}

We conducted two field trials to study two particular aspects in gameplay, namely co-presence and memorability.

\subsection{Co-presence}

The three situated displays in FT1 (Fig. 1) were placed in locations, which we expected to contain different levels of public attention. One display was in a secluded indoors location, second in a more crowded but still quiet place, while the third was placed in a location we expected to be very busy. To confirm that the sites actually had different levels of crowdedness, we counted the number of people passing the screens from the gathered video material (Table 2).

We acquired fewer co-presence samples around the displays in comparison to other datasets (game phases and game rounds), since we had to manually match locations with answers based on timestamps; we had to discard all answers we could not undeniably pair with a location. When using ANOVA with repeated measures and a Greenhouse-Geisser correction, we found that the mean co-presence scores between different display locations were statistically significantly different $(F=4.653, p=0.011)$. The results (Table 2$)$, suggest that the copresence was highest in the secluded location. A small difference was found between the quiet and busy locations.

The number of bystanders seems to reflect the disturbance the players experienced. Copresence score from the secluded location is the highest; this location had hardly anyone passing by when players were engaged in boss-fights. Although the difference in scores between the quiet and the busy location are smaller, they are still statistically significant.

The processes of developing joined strategies and becoming familiar with each other and the game may affect the players' sense of co-presence. When the scores are compared between game rounds, it can be seen that co-presence drops slightly from the first round towards to the last (Table 3). The mean scores in co-presence between different game rounds were statistically significantly different, albeit the differences were very small $(F=7.549, p=0.001)$.

Similar analysis was further conducted for co-presence between different game phases. Mauchly's test for sphericity indicated that the assumption of sphericity had not been violated, hence there was no need for corrections. The results (Table 4) show players reporting highest levels of co-presence during the quest phase. This is somewhat surprising, since the quest phase allows the players to roam individually contrary to other phases.

The overall differences between co-presence results are subtle, which can be seen in Fig. 8.

Table 2 Co-presence around different display locations

\begin{tabular}{|c|c|c|c|c|c|c|c|c|}
\hline \multirow[t]{2}{*}{ Display location } & \multirow[t]{2}{*}{ Passers-by } & \multirow[t]{2}{*}{$\mathrm{N}^{\mathrm{a}}$} & \multirow[t]{2}{*}{ Mean } & \multirow[t]{2}{*}{ Std. Error } & \multicolumn{2}{|c|}{$95 \%$ Confidence interval } & \multirow[t]{2}{*}{$\mathrm{F}$} & \multirow[t]{2}{*}{$\mathrm{p}$} \\
\hline & & & & & Lower & Upper & & \\
\hline Secluded (2) & 4 & 112 & 5.700 & 0.131 & 5.439 & 5.961 & 4.653 & 0.011 \\
\hline Quiet (6) & 121 & 201 & 5.180 & 0.114 & 4.954 & 5.406 & & \\
\hline Busy (1) & 268 & 100 & 5.450 & 0.123 & 5.207 & 5.693 & & \\
\hline
\end{tabular}

a The number of answered questionnaires, not the number of players 
Table 3 The co-presence between game rounds

\begin{tabular}{|c|c|c|c|c|c|c|c|}
\hline \multirow[t]{2}{*}{ Gameround } & \multirow[t]{2}{*}{$\mathrm{N}^{\mathrm{a}}$} & \multirow[t]{2}{*}{ Mean } & \multirow[t]{2}{*}{ Std. error } & \multicolumn{2}{|c|}{$95 \%$ Confidence interval } & \multirow[t]{2}{*}{$\mathrm{F}$} & \multirow[t]{2}{*}{$\mathrm{p}$} \\
\hline & & & & Lower & Upper & & \\
\hline 1. & 171 & 5.884 & 0.097 & 5.629 & 6.076 & 7.549 & 0.001 \\
\hline 2. & 263 & 5.523 & 0.100 & 5.326 & 5.720 & & \\
\hline 3. & 227 & 5.395 & 0.091 & 5.217 & 5.574 & & \\
\hline
\end{tabular}

a The number of answered questionnaires, not the number of players

\subsection{Co-presence: qualitative results}

The interviews gave us insight on what happened during different gamerounds and what may have been the true causes in differences in co-presence results. The joint goal of battle and colocated gameplay provided an environment for heightened engagement, allowing players to block outside disturbance. Sometimes the players reported paying attention to other teams while playing the game: "Was it like when we [were] fighting uhm.. some other group passed by they came to check the screen, but they went away." (FT1/ P22) however, more commonly the interviewees shrugged and commented on not noticing other players: "No, we didn't notice them..." (FT1/ $21 \mathrm{M})$.

When the players were asked about the differences between the first and the following game rounds, they stated that the first round was mainly about learning how to play the game. There was a shift in motivation from learning to play into winning, example excerpt of a discussion "It felt like at the start we tried like actually learn the game... "(FT1/22F). Another participant continued: "Yeah, the first round was pretty much learning but when we understood the core mechanics after that, the second round was more about winning. Especially the third one." (FT1/21 M). The learning curve of the played game also affected the chosen strategy for play, as stated by a player: "Our main strategy was actually the same on all three rounds. Uhm, not really. First we focused on the quests to get some money because we thought we would need some money for the equipment for the bosses, so we could actually beat them. But ehm, the first round was maybe more about the quests. The second round we also did two bossfights, I think... so it shifted toward winning the game maybe... yeah it was more about winning the game and experiencing the bosses." (FT1/22 M). It can be seen in the co-presence scores that the co-presence was highest during the quests phase. From the interviews, it became apparent that although the players would have been able to collect quest QRs independently, they did this activity together especially during the first two game rounds. The quest clues further offered the players a topic for conversations that strengthened social ties, quote: "Teamwork we did have in that we tried to find out where the quests were and otherwise we

Table 4 Co-presence between game phases and by the displays

\begin{tabular}{|c|c|c|c|c|c|c|c|}
\hline \multirow[t]{2}{*}{ Game phase } & \multirow[t]{2}{*}{$\mathrm{N}^{\mathrm{a}}$} & \multirow[t]{2}{*}{ Mean } & \multirow[t]{2}{*}{ Std. error } & \multicolumn{2}{|c|}{$95 \%$ Confidence interval } & \multirow[b]{2}{*}{$\mathrm{F}$} & \multirow[b]{2}{*}{$\mathrm{p}$} \\
\hline & & & & Lower & Upper & & \\
\hline Quests & 252 & 5.893 & 0.107 & 5.681 & 6.105 & 4.979 & 0.008 \\
\hline Conquering locations (pre-fight) & 272 & 5.507 & 0.115 & 5.279 & 5.735 & & \\
\hline Boss-fights (post-fight) & 140 & 5.429 & 0.098 & 5.234 & 5.623 & & \\
\hline
\end{tabular}

a The number of answered questionnaires, not the number of players 


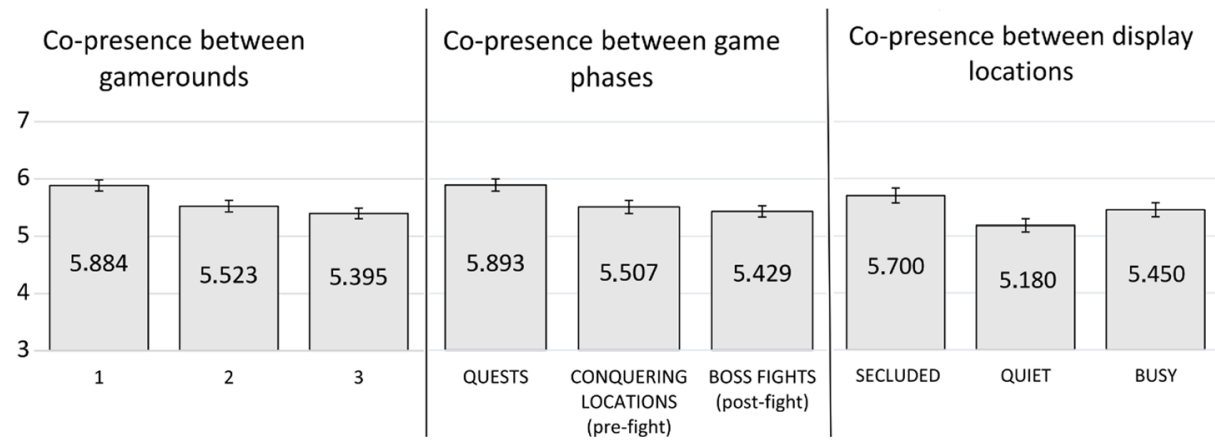

Fig. 8 Graphical presentation of the Co-presence results side by side. For clarity the scale of the graph is between 3 and 7

could have gone solo, but one can find the quest location much easier in groups, but that was something we could do alone and the last boss-fight got us together...” (FT1/26 M).

\subsection{Memorability and spatial similarity}

The coding schema for the interview material gathered after FT2 was adapted from the schema theory on memory on locations [10]. We added one category based on our initial observations, "Faulty recollection", on the players remembering locations wrong on occasion or admitting that they do not remember or are unable to recollect a scene. The categories and their explanations can be found from the following Table 5. We conducted parallel coding and agreement testing using point-by point agreement by Cohen's Kappa [5, 22] to note the interpretability of the material and the coding schema. The strength of agreement on recognizing on which scene was in question on each code was considered "very good". Number of observed agreements was 49/56 (88\%), the weighed Kappa value was 0,776 and the number of agreements expected by chance therefore $32 \%$. On the actual categories, the strength of agreement was considered "good". Number of observed agreements was 43/36 (77\%) and the weighed Kappa value was 0.647 .

It is notable that all the participating teams had a recollection of recognizing all the VEs (Table 3), they however were not able to name or describe the generic street corner scene (Fig. 5a) and on that particular VE they in fact had the highest frequency of faulty recognitions. The location with spatial realism (Fig. 5b) was at par with the VR that depicted a well-known location with landmarks (Fig. 5c).

How landmarks aid in recognition and recollection is apparent, example quote: "Yes, but the water was a bit away from the place. We were fighting at the market square closer to the market hall and the [well known statue by the site]." (FT2/ $24 \mathrm{M}$ ). The city was familiar to all the participants to some extend and having joined memory map aided in recollection when the comments from a fellow player could kindle memories. Spatial similarity may have not aided in a similar way, since sense of space is more subjective experience and the process of forming collective memory maps is therefore different. This would also explain why we were able to code more details remembered on the site B: Well-known location. The following quote highlights well how difficult it is to remember a specific location based on someone else's recollection of spatial qualities: "I was like yeah, I have been walking there, I know the place." (FT2/ 24F). Further the general naming of unknown locations is not very distinctive: here, there, somewhere, which also made interpretation of the interview material more difficult (Table 6). 
Table 5 Coding schema for memorability

\begin{tabular}{ll}
\hline Category & Description \\
\hline Recollection & Subject states they remember recognizing a location \\
Recognition & Subject recognizes and names the location \\
Details remembered & Subject remembers and mentions details, landmarks, location etc. \\
Faulty recollection & Subject remembers a location or a detail from that location wrong. \\
& Or admits not remembering the location at all. \\
\hline
\end{tabular}

\subsection{Further observations}

We enquired from the participants in the FT2 how important they thought it was for the gameplay to have the virtual scenes on familiar locations to which they all replied with varying level of enthusiasm that they found the use of familiar sites fun and interesting; an example quote from one of the players: "My first location based game, and when those virtual world locations were according to the real locations it was more interesting." (FT2/20F). During the interview, one of the participants also described how she had imagined that she is walking in the VE scene while leaving the display after a boss-fight and, for a moment, the two scenes were linked in her mind, as she had entered the scene from that same location.

While the players interacted with their team members, they had only little interaction amongst the other teams and bystanders. In FT1, the players had the following discussion when enquired about the other teams: "Well, once we saw them or two times, but we didn't do anything special when we saw them." (FT2/ M21) "Yeah, it was kind of weird, that we lost other teams when we left here. I think it was kind of good but during the last round we were going through the market square... we... There was one team passing by and they actually got one of our "nodes" our points there and we fought back but they didn't stay so we just won that place. But no other conflict really." (FT2/ M22). A typical situation with bystanders can be described by this comment from the FT2: "Yeah, especially in [shopping mall] there was a lot of teenage boys and girls and they were like,...: 'What the fuck is this?' I could hear them talking. They were watching the screen and they noticed that we were playing that and...". (FT1/24 M) While the displays drew attention, the players were more often interrupted while they were doing the quests: "I think

Table 6 Results from the coding and example quotes from the material

\begin{tabular}{|c|c|c|c|c|}
\hline \multirow[t]{2}{*}{ Category } & \multicolumn{3}{|l|}{ Frequencies } & \multirow[t]{2}{*}{ Quote } \\
\hline & $\begin{array}{l}\text { Well know location } \\
\text { with spatial } \\
\text { similarity }\end{array}$ & $\begin{array}{l}\text { Well- } \\
\text { known } \\
\text { location }\end{array}$ & $\begin{array}{l}\text { Generic } \\
\text { street } \\
\text { corner }\end{array}$ & \\
\hline Recollection & 10 & 7 & 7 & $\begin{array}{l}\text { "Yeah, they were places from [Anonymized]." } \\
\text { (FT2: Player ID } 24 \mathrm{M})\end{array}$ \\
\hline Recognition & 6 & 4 & 0 & $\begin{array}{l}\text { "When we were at [Anonymized], I think we were } \\
\text { in the market square in the game." (FT2: } 24 \mathrm{M} \text { ) }\end{array}$ \\
\hline $\begin{array}{l}\text { Details } \\
\text { Remem- } \\
\text { bered }\end{array}$ & 3 & 6 & 0 & $\begin{array}{l}\text { "This [Anonymized] was good, when I saw it I was } \\
\text { like: Oh, its [Anonymized]. Like I started there in } \\
\text { front of this place." (FT2: } 20 \mathrm{M} \text { ) }\end{array}$ \\
\hline $\begin{array}{l}\text { Faulty } \\
\text { recollec- } \\
\text { tion }\end{array}$ & 4 & 1 & 8 & $\begin{array}{l}\text { "Oh yeah, it was behind the city hall!" (It was not) } \\
\text { (FT2: } 20 \mathrm{M} \text { ) } \\
\text { "And I don't remember the library one, but we only } \\
\text { did it once." (FT2: } 24 \mathrm{M} \text { ) }\end{array}$ \\
\hline
\end{tabular}


during the boss-fights people were observing us, but they didn't want to disturb us or something. So, no one would ask us. But after, when we were doing the quests, after scanning the QRs, they'd ask us." (FT1/23 M). The players in this case were asked by a father who was observing them with his two children," whether they were playing Pokemon GO, too". The players also reported observing bystanders to scan the quest codes to see what they were. This could mean that we missed an opportunity to engage the audience in gameplay.

\section{Discussion}

Pervasive games are entwined with everyday life and the boundaries of virtual and physical are blurred [37]. We can assume that game developers in general aspire high presence that relates to high immersive qualities of the game environment or how the VEs are projected. Pervasive games are said to aim at blurring boundaries between real and play, but we cannot assume that successful blurring of those boundaries is a measure of successful pervasive game. However, if this is the aim of a developer of pervasive games, then smooth attention displacement should be pursued in moving between virtual and physical realms. Our goal was to study the factors involved in smooth attention flow when pervasive gameplay shuttles between physical and virtual environments. We hope to close the seam between the virtual and the physical by allowing the players to step into the virtual environment in a way that the blending of the virtual and real is done gradually to ease into the more fantastic environment of a boss-fight or perhaps, in other applications, into the more abstract virtual environments.

\subsection{Co-presence in the context of pervasive games}

If blurring boundaries between realities and daily life is the aim of a developer of a pervasive game, then smooth attention displacement when moving between virtual and physical realms should be the goal. The experience of presence persists throughout daily life. It is suggested that presence is measurable as a binary target, it is either sensed or not $[16,39,52,56]$. Therefore, we focused on more quatifiable and observable co-presence. The difficulties in observing co-presence in the context of pervasive games is clear from the results. Different game rounds produce different results, but the cause is not apparent. Since we applied in the wild methodology, we were able to benefit from combining both quantitative and qualitative data, which resulted into a more detailed description of the events in the field. This also gave us an insight on what affected co-presence. It was found that players do observe their surroundings to some extent, even when they seem to be engaged in gameplay. The co-presence in a secluded location gave the highest results in experienced co-presence. The subtle differences in results, such as shown when co-presence is compared between game rounds, can easily be caused by other environmental factors, we did not record. Complementing ESM with interviews gave us an insight on what caused differences in experienced co-presence, but it also gave us a wider view on the complexity of experimental setup in the streets. Learning to play the game brought the players together at first, but as the player strategies and confidence developed, the co-presence experience diminished. 


\subsection{Memorability and stepping into the virtual}

Navigation in VEs has its challenges [47, 57], navigation between the physical and virtual environments brings an added challenge. Our results show (Table 4) the familiarity and landmarks of a scene worked expectedly, and the players did not just remember the VE location but could remember details and describe the location better than with just a generic street corner scene. From the results one can conclude that spatial realism is important when embedding VEs into pervasive games in a memorable way. It is notable that when the players had observed the game scene from the generic street corner they could only remember recognizing the scene but were unable to recollect any details. Furthermore, quite a few of them later in the interview admitted that they do not remember that particular VE at all. Our findings therefore suggest that spatial realism is one of the semantic features of virtual environment affecting the memorability of VEs in the context of pervasive games.

\subsection{Embedding VEs into the context of pervasive games}

We recognize two important issues to consider in embedding VEs into the urban playground: structuring of social interactions and the realism of the VEs.

\subsubsection{Structuring of social interaction}

The social aspect of pervasive and location based mobile games is an important motivator for the players. The sight of Pokemon GO players swarming in same location, and seemingly socializing with both familiar and unknown players, is familiar to us. It can perhaps raise assumptions that people playing digital games in the physical world are mainly there to create new contacts. While in Geocaching, the social motivator may be making new friend and indirect communication with strangers, in Pokemon GO it has been observed that the gameplay strengthens ties with people the players are already familiar with [43, 57]. We observed that secluded setting with little outside influence yielded higher co-presence within the team for the players. However, even when the players did not claim on paying attention to others, the co-presence scores according to different locations indicate that the players do acknowledge their surroundings. Furthermore, this affects the centrality of their attention. The levels of social interaction in gameplay should be taken into consideration when designing pervasive games both, when embedding VEs into the game design, but also when planning the purpose of those VEs and the overall game mechanics. If the VE is embedded into a more secluded setting, it may strengthen the social binding between the team of players. However, if one situates the VE into a busier setting, it can be more useful for generating new social connections. In these cases, the $\mathrm{VE}$ or its game mechanics could be used to engage the audience in addition to the players.

The social aspects of player experience can be rewarding for the players. In addition, the games can contribute to positive behaviour change when battling depression or social withdrawal $[43,57]$. It can be beneficial to explore what are the game mechanics in pervasive games that provide an environment where co-presence is optimal, depending whether the aim is to strengthen existing ties or to make new friends.

\subsubsection{Spatial realism of the VEs}

Realism of a game scene e.g. the VE can vary from proportionally correct map-based visualization to $3 \mathrm{D}$ city scene that is realistic at the street level, where it is viewed and accessed. One must take 
into consideration that there is a difference between recognizing, recollecting, and remembering. When a player recognizes the VE but does not remember it, or is not able to describe it, one can assume that the impact of the VE has been low. When a player remembers the VE and can describe it in detail, the impact has been high and there is a possibility for a further structuring of mental maps of the VEs. We noticed that at the level of highly realistic embedded VEs, the spatial realism is equally important for memorability as is the already established connection between memorability and known landmarks in the VE [58]. We suggest spatial similarity of the projected VEs to the physical access point as one solution for smooth transition between the two realities. Albeit, mobile screens are more portable, and a map projection of locations does offer a smoother transition between realities, pervasive displays can in addition provide a site for co-located gameplay for the players and heighten their sense of co-presence and social presence. In the future, it would be interesting to survey what are the most viable platforms for projecting VEs in pervasive games. As smart phones are effectively small computers with 3D rendering capabilities, there should be other more imaginative options for utilizing the city infrastructure in pervasive games. This could potentially help combat the effect mobile games have on attention on the physical environment [40] by shifting attention away from the phone screen and more to the actual context of the gameplay, the city, and the people.

\subsection{Limitations and future work}

We acknowledge that our study has both small sample of participants and small sample of games. In the future we would like to observe what happens during the transitions between physical and virtual realms, when more players engage in different kinds of games and we can focus on further measurable aspects in player experience. Perhaps this would result into being able to outline the shape of the more difficult to measure aspects of pervasive games, such as flow. We would also like to extend the influence that the VE contents has to the physical environment, which could be achieved by allowing remote participation and communication via the VEs on displays. As previous studies in a more restricted setting show, this might result into more dynamic social interactions between the players [48]. Furthermore, as we noticed in our study, the co-located gameplay does not necessarily enhance the sense of co-presence.

Our analysis of how the players recalled the VE game arenas is based on interview data only. We believe that differences in the level of memorability correlates with the spatial similarity of the VEs to the physical locations where the boss-fights were conducted. However, there may be other aspects in game play that affected the memorability of those scenes, such as the contents of the discussions the players had while searching the bossed in VE. We missed the opportunity to record those discussions. However, we believe that the effect of the discussions on the memorability would have had a similar correlation as the complexity and the spatial realism of the game scenes had on memorability. In point-by-point agreement testing, the expected agreements by chance on our coding is $32 \%$, which suggests that there is room for interpretation in our coding schema and results.

Pervasive games have many subgenres [37]. We chose a pervasive digital LARP as a contruct in our stydy, as this game construct had been specifically designed to facilitate research. In addition the gameplay is divided into differing phases, which makes it possible to observe gameplay from location-based exploration (the quest phase) to battle where VEs and the physical space are joined in a mixed- or hybrid reality game (the boss fights). We do admit however that similar results in memorability and co-presence may not be observable in pervasive games that differ considerably from the most base-line pervasive games. For instance, pervasive games where 
the context of gameplay is not extended, but in fact turned inwards, may facilitate completely different modes for co-presence and memorability than pervasive LARPs. Such is the case for instance with Gutsgame [33]. It is a bodily pervasive game that through ingestible sensor makes body's core temperature visible to the player. The altering context of pervasive games would offer and interesting opportunity for future surveys on how co-presence or memorability.

\section{Conclusion}

There is a connection between memorability, presence, and immersion. All of which are important for a game to have an impact on the players. While designing and embedding VEs into the context of pervasive games, it is important to acknowledge the impact of physical and virtual environments to the player experience. We conducted two field trials in the wild to explore co-presence in gameplay as well as the memorability of the embedded VEs with City Knights game with 22 participants in two separate trials.

The memorability of the spatially realistic scene compares to that of already established connection between the VE scenes with landmarks, however recollecting details of the scene seems to be easier from a familiar scene with well-known landmarks.

City Knights has three distinct phases that vary in how they are designed to facilitate copresence and interaction. In our experiment we noticed that co-located gameplay near situated displays did not result in higher co-presence. Face-to-face -interaction while jointly doing quests resulted into a higher sense of co-presence. As the game progressed and the players began to do quests solo, as well as to remember locations from earlier game round(s), a change in co-presence could be seen as a dip over time. Although the players stated in the interviews that they did not pay much attention to other players, a secluded setting for accessing the VE resulted in a higher co-presence.

As a conclusion, we emphasize two important issues to consider in embedding VEs into the context of pervasive games, structuring of social interactions and the realism of the VES.

Acknowledgements Open access funding provided by University of Oulu including Oulu University Hospital. This work has been supported by the Open Innovation Platforms spearhead project (A70202) and the Open City Model as Open Innovation Platform project (A71143) funded by the ERDF and the City of Oulu under the Six City Strategy program, and the COMBAT project (293389) funded by the Strategic Research Council at the Academy of Finland. The authors would also like to show appreaciation to the test participants.

Open Access This article is distributed under the terms of the Creative Commons Attribution 4.0 International License (http://creativecommons.org/licenses/by/4.0/), which permits unrestricted use, distribution, and reproduction in any medium, provided you give appropriate credit to the original author(s) and the source, provide a link to the Creative Commons license, and indicate if changes were made.

Publisher's Note Springer Nature remains neutral with regard to jurisdictional claims in published maps and institutional affiliations.

\section{References}

1. Alatalo T, Koskela T, Pouke M, Alavesa P, Ojala T (2016) VirtualOulu: collaborative, immersive and extensible 3D city model on the web. In: Proceedings of the 21st International Conference on Web3D Technology. ACM, Anaheim, California, p 95-103. https://doi.org/10.1145/2945292.2945305 
2. Alatalo T, Pouke M, Koskela T, Hurskainen T, Florea C, Ojala T (2017) Two real-world case studies on 3D web applications for participatory urban planning. In: Proceedings of the 22nd International Conference on 3D Web Technology. Brisbane, Queensland, Australia: ACM.doi: https://doi.org/10.1145/3055624.3075950, p 1-9

3. Alavesa P, Ojala T (2015) Street art gangs: location based hybrid reality game. In: Proceedings of the 14th International Conference on Mobile and Ubiquitous Multimedia. ACM, Linz, Austria, p 64-74. https://doi. org/10.1145/2836041.2836047

4. Alavesa P, Pakanen M, Voroshilov A, Kukka H, Samodelkin A, Ojala T, Pouke M (2017). City knights: spatial realism of a virtual game scene and memorability while playing a pervasive role playing game. In: Games and Virtual Worlds for Serious Applications, 2017 9th International Conference on. IEEE, Athens, p 71-78. doi:https://doi.org/10.1109/VS-GAMES.2017.8055813

5. Bakeman R, Quera V (2011) Sequential analysis and observational methods for the behavioral sciences. Cambridge University Press, New York

6. Beaulieu A (2010) Research note: from co-location to co-presence: shifts in the use of ethnography for the study of knowledge. Soc Stud Sci 40:453-470

7. Benford S, Crabtree A, Flintham M et al (2006) Can you see me now? ACM Trans Comput-Hum Interact 13:100-133. https://doi.org/10.1145/1143518.1143522

8. Biljecki F, Ledoux H, Stoter J, Zhao J (2014) Formalisation of the level of detail in 3D city modelling. Comput Environ Urban Syst 48:1-15. https://doi.org/10.1016/j.compenvurbsys.2014.05.004

9. Brade J, Lorenz M, Busch M et al (2017) Being there again - presence in real and virtual environments and its relation to usability and user experience using a mobile navigation task. Int J Hum Comput Stud 101:7687. https://doi.org/10.1016/j.ijhcs.2017.01.004

10. Brewer WF, Treyens JC (1981) Role of schemata in memory for places. Cogn Psychol 13:207-230. https://doi.org/10.1016/0010-0285(81)90008-6

11. Callon M, Rabeharisoa V (2003) Research "in the wild" and the shaping of new social identities. Technol Soc 25:193-204. https://doi.org/10.1016/S0160-791X(03)00021-6

12. Casanueva J, Blake E (2000) The effects of group collaboration on presence in a collaborative virtual environment. In: Mulder J, Liere R (eds) Virtual Environments 2000: Proceedings of the Eurographics Workshop in Amsterdam, The Netherlands, June 1-2, 2000. Springer Vienna, Vienna, p 85-94

13. Chamberlain A, Crabtree A, Rodden T, et al (2012) Research in the wild: understanding "in the wild" approaches to design and development. In: Proceedings of the Designing Interactive Systems Conference. ACM, Newcastle Upon Tyne, United Kingdom, p 795-796. https://doi.org/10.1145/2317956.2318078

14. Crabtree A, Benford S, Rodden T, Greenhalgh C, Flintham M, Anastasi R, ... Steed A (2004) Orchestrating a mixed reality game "on the ground." In: Proceedings of the SIGCHI Conference on Human Factors in Computing Systems. ACM, Vienna, p 391-398. https://doi.org/10.1145/985692.985742

15. Csikszentmihalyi M (1997) Finding flow. Basic Books, New York

16. Cummings JJ, Bailenson JN (2016) How immersive is enough? A meta-analysis of the effect of immersive technology on user presence. Media Psychol 19:272-309. https://doi.org/10.1080/15213269.2015.1015740

17. de Souza e Silva A (2009) Hybrid reality and location-based gaming: redefining mobility and game spaces in urban environments. Simul Gaming 40(3):404 424. https://doi.org/10.1177/1046878108314643

18. de Souza e Silva A, Sutko DM (2008) Playing life and living play: how hybrid reality games reframe space, play, and the ordinary. Crit Stud Media Commun 25(5):447-465. https://doi.org/10.1080 /15295030802468081

19. Fallout 4 (2015) Rockville, Maryland, U.S: Bethesda Game Studios

20. Farman J (2013) Mobile interface theory: embodied space and locative media. Routledge, London

21. Feiner S, MacIntyre B, Haupt M, Solomon E (1993) Windows on the world: 2D windows for 3D augmented reality. In: Proceedings of the 6th annual ACM symposium on User interface software and technology. ACM, Atlanta, Georgia, USA, p 145-155. https://doi.org/10.1145/168642.168657

22. Fleiss JL, Levin B, Paik MC (2013) Statistical methods for rates and proportions. John Wiley \& Sons, Hoboken

23. Gajadhar BJ, Kort YAW, IJsselsteijn WA (2008) Shared fun is doubled fun: player enjoyment as a function of social setting. In: Markopoulos P, Ruyter B, IJsselsteijn W, Rowland D (eds) Fun and Games: Second International Conference, Eindhoven, The Netherlands, October 20-21, 2008. Proceedings. Springer Berlin Heidelberg, Berlin, Heidelberg, p 106-117. https://doi.org/10.1007/978-3-540-88322-7_11

24. Geiger P, Schickler M, Pryss R, Schobel J, Reichert M (2014) Location-based mobile augmented reality applications: Challenges, examples, lessons learned. In: 10th Int'l Conference on Web Information Systems and Technologies (WEBIST 2014), Special Session on Business Apps. Barcelona, Spain, p 383-394

25. Gelernter D (1993) Mirror worlds: or: the day software puts the universe in a shoebox... How it will happen and what it will mean. Oxford University Press, New York City

26. Goerger S, Darken RP, Boyd M, Gagnon T, Liles S, Sullivan J, Lawson J (1998) Spatial knowledge acquisition from maps and virtual environments in complex architectural spaces. In: Proceedings of the 16th Applied Behavioral Sciences Symposium. U.S. Airforce Academy, Colorado Springs, US 
27. Goffman E (1963) Behavior in public places. Free Press, New York

28. Grand Theft Auto V. (2013) Rockstar North Ltd., Edinburgh

29. Heeter C (1992) Being there: the subjective experience of presence. Presence Teleop Virt 1:262-271. https://doi.org/10.1162/pres.1992.1.2.262

30. Hektner JM, Schmidt JA, Csikszentmihalyi M (2007) Experience sampling method: measuring the quality of everyday life. Sage, Thousand Oaks

31. Isola P, Parikh D, Torralba A, Oliva A (2011) Understanding the intrinsic memorability of images. In: Advances in neural information processing systems. p 2429-2437

32. Kasapakis V, Gavalas D (2015) Pervasive gaming: status, trends and design principles. J Netw Comput Appl 55:213-236. https://doi.org/10.1016/j.jnca.2015.05.009

33. Li Z, Brandmueller F, Greuter S, Mueller F (2018) The guts game: designing playful experiences for ingestible devices (p. VS12). Presented at the Extended Abstracts of the 2018 CHI Conference on Human Factors in Computing Systems, ACM

34. Ling N, Chen S-C, Park D-S (2016) Guest editorial: pervasive multimedia computing — systems applications and services. Multimed Tools Appl 75:14015-14017

35. Mania K, Robinson A, Brandt KR (2005) The effect of memory schemas on object recognition in virtual environments. Presence Teleop Virt 14:606-615. https://doi.org/10.1162/105474605774918769

36. Mapgets. In: Mapgets. http://mapgets.com. Accessed 20 Oct 2016

37. Montola M, Stenros J, Waern A (2009) Pervasive games: theory and design. Morgan Kaufmann Publishers Inc, Burlington

38. Nakamura J, Csikszentmihalyi M (2009) Flow theory and research. In: Snyder CR, Lopez SJ (eds) Handbook of positive psychology. Oxford University Press, New York, pp 195-206

39. Neustaedter C, Tang A, Judge TK (2013) Creating scalable location-based games: lessons from geocaching. Pers Ubiquit Comput 17(2):335-349. https://doi.org/10.1007/s00779-011-0497-7

40. Nickerson RC, Isaac H, Mak B (2008) A multi-national study of attitudes about mobile phone use in social settings. Int J Mob Commun 6(5):541-563. https://doi.org/10.1504/IJMC.2008.019321

41. Nitsche M (2008) Video game space: image, play, and structure in 3D game worlds. MIT Press, Cambridge

42. Nowak KL, Biocca F (2003) The effect of the agency and anthropomorphism on users' sense of telepresence, copresence, and social presence in virtual environments. Presence Teleop Virt 12(5):481494. https://doi.org/10.1162/105474603322761289

43. O'Hara K (2008) Understanding geocaching practices and motivations. In: Proceedings of the SIGCHI Conference on Human Factors in Computing Systems. ACM, Florence, Italy, p 1177-1186. https://doi. org/10.1145/1357054.1357239

44. Paavilainen J, Korhonen H, Alha K, Stenros J, Koskinen E, Mäyrä F (2017) The Pokemon GO experience: a location-based augmented reality mobile game goes mainstream. In: Proceedings of the $2017 \mathrm{CHI}$ Conference on Human Factors in Computing Systems. ACM, Denver, Colorado, USA, p 2493-2498. https://doi.org/10.1145/3025453.3025871

45. Pokemon Go (2016) Niantic

46. Richardson I (2011) The hybrid ontology of mobile gaming. Convergence 17(4):419-430. https://doi. org/10.1177/1354856511414797

47. Richardson AE, Montello DR, Hegarty M (1999) Spatial knowledge acquisition from maps and from navigation in real and virtual environments. Mem Cogn 27:741-750. https://doi.org/10.3758/BF03211566

48. Sakamoto M, Alexandrova T, Nakajima T (2016) Analyzing the influence of virtuality on playful social interaction. Multimed Tools Appl 75:8289-8317. https://doi.org/10.1007/s11042-015-2751-x

49. Samodelkin A, Alavesa P, Voroshilov A (2016) A platform for pervasive games for research. In: Proceedings of the 15th International Conference on Mobile and Ubiquitous Multimedia. ACM, Rovaniemi, p 335-337. https://doi.org/10.1145/3012709.3016066

50. Skopik A, Gutwin C (2003) Finding things in fisheyes: memorability in distorted spaces. In: Conference on Graphics Interface GI'03. Halifax, Nova Scotia, Canada, p 67-75

51. Slater M (2002) Presence and the sixth sense. Presence Teleop Virt 11(4):435-439. https://doi.org/10.1162 $/ 105474602760204327$

52. Slater M, Steed A (2000) A virtual presence counter. Presence Teleop Virt 9(5):413-434. https://doi. org $/ 10.1162 / 105474600566925$

53. Slater M, Usoh M, Steed A (1994) Depth of presence in virtual environments. Presence Teleop Virt 3(2): 130-144. https://doi.org/10.1162/pres.1994.3.2.130

54. Uden M, Zipf A (2013) Open building models: towards a platform for crowdsourcing virtual 3D cities. In: Progress and New Trends in 3D Geoinformation Sciences. Springer, p 299-314. https://oi.org/10.1007 1978-3-642-29793-9 17

55. Unity (2005) San Francisco, California, U.S: Unity Technologies 
56. Usoh M, Catena E, Arman S, Slater M (2000) Using presence questionnaires in reality. Presence Teleop Virt 9(5):497-503. https://doi.org/10.1162/105474600566989

57. Vella K, Johnson D, Cheng VWS, Davenport T, Mitchell J, Klarkowski M, Phillips C (2017) A sense of belonging: Pokémon GO and social connectedness. Games and Culture. https://doi.org/10.1177 $/ 1555412017719973$

58. Vinson NG (1999) Design guidelines for landmarks to support navigation in virtual environments. In: Proceedings of the SIGCHI conference on Human Factors in Computing Systems. ACM, Pittsburgh, Pennsylvania, USA. p 278-285. https://doi.org/10.1145/302979.303062

59. Witmer BG, Singer MJ (1998) Measuring presence in virtual environments: A presence questionnaire. Presence Teleop Virt 7(3):225-240. https://doi.org/10.1162/105474698565686

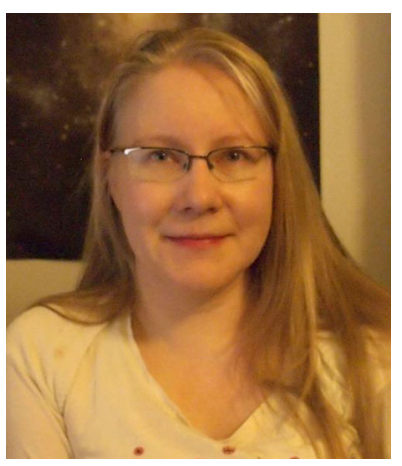

Paula Alavesa is a $\mathrm{PhD}$ candidate at Center for Ubiquitous Computing in University of Oulu, Finland. She received MSc in computer science in 2013 and MSc in Biochemistry 2008 from University of Oulu, Finland. Her research interests are in pervasive gaming, game design player experience and 3D graphics.

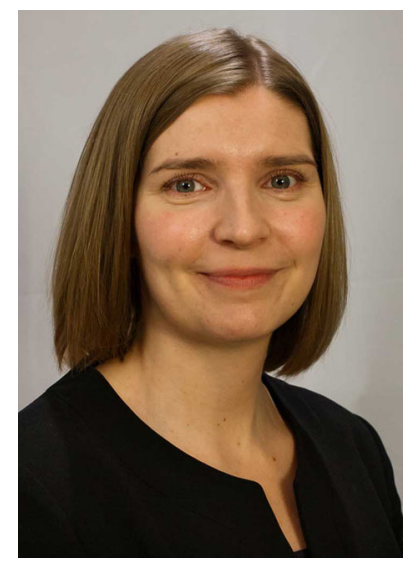

Minna Pakanen is a Postdoctoral researcher at University of Oulu, Center for Ubiquitous Computing. Her background is in design with a master's degree in industrial design from the University of Lapland in 2011. She received her $\mathrm{PhD}$ in information processing science 2015. Her research interests include anticipated user experience, interaction and visual user interface design, 3D user interfaces, internet of things, and ubiquitous computing. 


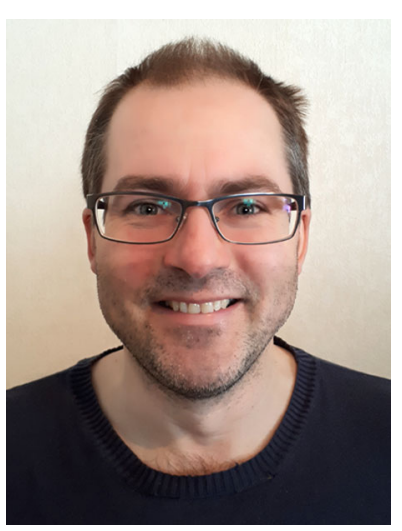

Timo Ojala is a Professor of computer science and engineering and the Director of the Center for Ubiquitous Computing in the University of Oulu. He received his Dr. degree in electrical engineering from the University of Oulu in 1997. His research interests include human-computer interaction, ubiquitous computing and hybrid reality. He is a member of the ACM.

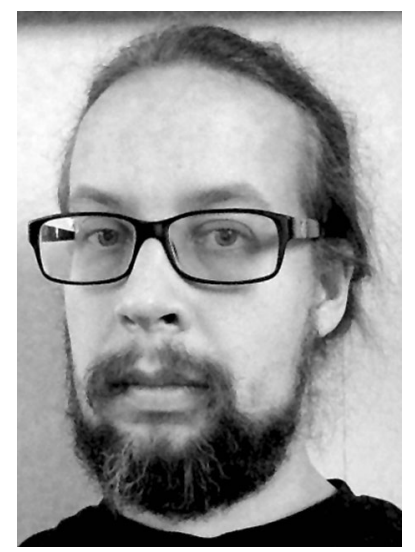

Matti Pouke received BSc, MSc and $\mathrm{PhD}$ degrees in information processing science from University of Oulu, Finland, in 2008, 2009 and 2015 respectively. He studied 3D graphics in Hokkaido University 2006-2007 as well as machine learning and augmented virtuality in Nara Institute of Science and Technology from 2010 to 2011 and 2013. Currently he is a Postdoctoral Researcher in Center for Ubiquitous Computing, University of Oulu, Finland. His current research interests are in 3D City models, Virtual Reality, and Cybersickness. 


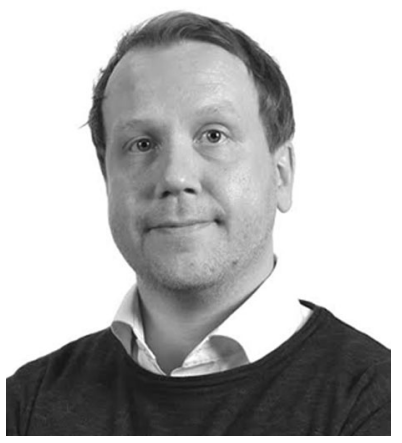

Hannu Kukka received his PhD degree in Computer Science from the University of Oulu in 2012. Since then he has worked in the Carnegie Mellon University School of Computer Science as a post-doctoral researcher, and at the University of Oulu as an adjunct professor. He is currently employed as the UX Design Lead at Boogie Software Ltd. Hannu's research interests include ubiquitous and urban computing, with a focus on humancomputer interaction in smart urban spaces.

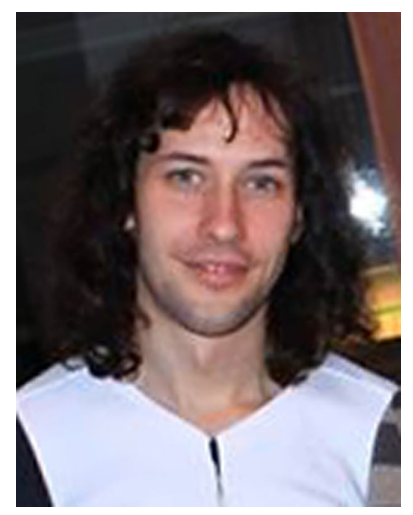

Alexander Samodelkin received a MSc degree in Computer Science from University of Oulu, Center for Ubiquitous Computing 2017. He is currently employed as a software engineer at Adminotech Ltf. 


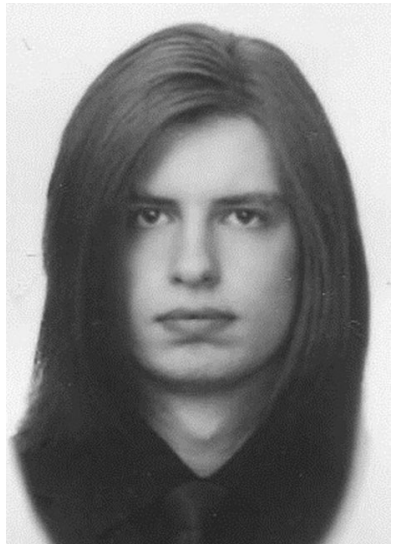

Alexander Voroshilov received a MSc degree in Computer Science from University of Oulu, Center for Ubiquitous Computing 2017. His research interests are HCI, deep learning, and information theory.

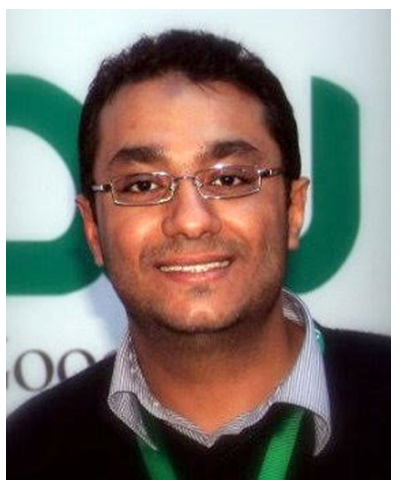

Mohammed Abdellatif, is pursuing a MSc degree in Computer Science and Engineering from University of Oulu, Center for Ubiquitous Computing. He is currently working on his thesis studying the effects of prolonged use of Virtual Reality headsets. His research interests are Virtual Reality, Usability and Embedded Systems. 